\title{
PALABRAS LIMINARES
}

Cuando en 1985 el maestro Alfredo Roggiano, cuya inolvidable presencia valga aquí rememorar una vez más, me invitó a dirigir este número especial dedicado a la literatura venezolana, sentí la mayor alegría porque su generoso ofrecimiento celebraba mi admiración constante por el hacer literario de Venezuela, el cual era tema de nuestro frecuente diálogo en la Universidad de Pittsburgh. Como es bien sabido por mis amigos venezolanos, Venezuela fue y sigue siendo patria de mis más profundos afectos, desde que en 1969 me abrió sus puertas y por largos y fructíferos diez años soportó el peso de mis suelas por sus calles y carreteras.

Asimismo, su invitación me permitía, en balance, poder contribuir ante el mundo literario internacional con un número que fuese una visión crítica procedente, en su mayor parte, del interior de la realidad intelectual y espiritual del país. No está de más recordar que Venezuela, a lo largo de nuestra historia independiente, ha participado como el que más en la creación de un pensamiento y de una expresión de lo nuestro; así lo atestiguan no sólo los que forjaron la independencia de América sino aquéllos que con su pensamiento y creación son hitos fundamentales de nuestro ser americano.

No sabía en aquel entonces, mientras caminaba por Caracas dialogando con amigos sobre este proyecto, que la empresa total llevaría un buen número de años, que el maestro Roggiano ya no estaría con nosotros para ver el resultado final, y que al ampliar el número de editores e incluir a Alexis Márquez Rodríguez y a Antonio López Ortega, lograría cumplir a cabalidad con el propósito inicial que, siguiendo la línea académica de la Revista Iberoamericana, quería siempre la mayor apertura para todos los integrantes del mundo literario venezolano.

La presencia de ellos, pues, ha sido fundamental. Sin el conocimiento y la devoción crítica constructiva de Alexis, y sin el entusiasmo inteligente y el empuje dinámico de Antonio, este número sería otra cosa. Largas jornadas de trabajo, aunadas a su gran amor y pasión por su propia literatura, subyacen en estas páginas. Madurez y juventud han sido pues los motores que han impulsado este número y que nos permiten ver, un paso más allá de la maestría de Rómulo Gallegos, como se ha ido forjando una literatura que se afirma valiosamente en el siglo $\mathrm{XX}$ a la vez que se abre con gran fuerza y profundidad hacia el nuevo siglo que ya se nos viene encima. 
Como dije anteriormente, este número partió de la idea de incluir, en lo posible, la mayor cantidad de críticos y escritores de toda tendencia y orientación. Creo que hemos logrado ampliamente nuestro propósito. Sin embargo, hecho el balance final vemos que la falta de artículos e informativos sobre el teatro venezolano es algo que tenemos que lamentar. No fue ésa nuestra intención, obviamente. Las circunstancias así lo impusieron.

Este número no hubiera sido posible sin el entusiasmo y la paciencia de Keith McDuffie, director de la Revista Iberoamericana, y de Pamela Bacarisse, SecretariaTesorera del Instituto Internacional de Literatura Iberoamericana. Queremos agradecer también la valiosa colaboración de Beatriz González, solidaria desde un comienzo con esta empresa y empeñada firmemente en lograr su mejor resultado.

La portada es de Mario Abreu, el pintor venezolano recientemente fallecido. Mario hizo con su vida y con su obra un homenaje constante a la poesía y a la literatura venezolanas; él fue inspiración, modelo, guía. Viva su espíritu siempre con nosotros.

ARMANDO ROMERo 